\title{
Insight \\ Rethinking Partnerships with the Aim of Producing Knowledge with Practical Relevance: a Case Study in the Field of Ecological Restoration
}

\author{
$\underline{\text { Héloïse Gonzalo-Turpin }}^{1}, \underline{\text { Nathalie Couix }}^{2}$, and Laurent Hazard ${ }^{1}$
}

\begin{abstract}
Researchers in conservation biology and restoration ecology often work in partnership with local actors to increase the practical relevance of the knowledge they produce. Although an academic mode of knowledge production is essential in research for a better understanding of biological systems, it often fails to produce frameworks and methodologies having practical relevance that can be used in conservation and restoration programs. The involvement of researchers in collective plans of action is supposed to contribute to the production of a more contextualized form of knowledge. In this paper, we report our experience of partnership research in an ecological restoration project. We show that changing our mode of knowledge production to one that produces knowledge having more practical relevance requires a particular spectrum of partners and reflexive communication between all the partners. We advocate the need for participatory approaches that favor collective and reflexive processes of problem finding and problem solving in conservation and restoration projects. Putting such processes into practice is not only a challenge for researchers but also for their partners, and presupposes a profound transformation of their roles.
\end{abstract}

Key Words: conservation biology; genetic resources; local seeds; mode of knowledge production; native species; problem-finding; Pyrenees; seed transfer zones; stakeholders

\section{INTRODUCTION}

The conservation and restoration of threatened biological systems has emerged as a major scientific and societal issue during the last decade. The challenge for conservation biologists and restoration ecologists is to produce knowledge that can be effectively implemented when dealing with this issue (Higgs 2005, Robinson 2006). Although the use of an academic mode of knowledge production in research is essential for a better understanding of biological systems, it often fails to produce frameworks and methodologies of practical relevance that can be used in conservation and restoration programs (Geist and Galatowitsch 1999, Gobster and Hull 1999, Robinson 2006, Cabin 2007). Using Rhoades' (1989) example, most scientists may know how potatoes grow but they fail to earn their living growing them as a farmer does. Even when research programs are designed to guide conservation or restoration actions, realworld complexities often limit the operational relevance of the academic mode of knowledge production (Gobster and Hull 1999, Robinson 2006, Cabin 2007). To increase the practical relevance of their research, more and more conservation biologists and restoration ecologists are collaborating with local actors who know the field. Without this partnership, scientists often fail to grasp the complexity and the specificity of a problem occurring at a given site (Higgs 1997, 2005, Chan et al. 2007). By collaborating with local partners, they can first collectively identify the local problems and then look for pertinent solutions for this given context. Paraphrasing Rhoades (1989), the research questions shift from the academic type - "how do potatoes grow?"- to more complex and transdisciplinary types- "how do we grow potatoes?" Conservation biology (CB) and restoration ecology (RE) paradigms acknowledge this real-world complexity (for CB, see Robinson 2006; for ER, see Choi 2007, Temperton 2007), in which human factors must be explicitly considered (Robertson and Hull 2001). 
Several authors have proposed different theoretical frameworks concerning the form of knowledge production that emerges in partnership research (see review by Hessels and van Lente 2008). Gibbons et al. (1994) and Nowotny et al. (2001) proposed a synthetic theory in which they identified two modes of knowledge production, Mode-1 and Mode-2. Mode- 1 is carried out in a scientific, disciplinebased framework. It favors academic research, partially disconnected from its potential context of application. In the short term, Mode-1 is often irrelevant to the production of operational and socially relevant knowledge (Nowotny et al. 2001). In contrast, Mode- 2 starts from the problems posed in their context of application, by the different stakeholders, and necessitates partnership research. Nevertheless, very few authors have reported their concrete experience of partnership research associated with their attempt to change their mode of knowledge production.

In this paper, we report our experience of partnership research in an ecological restoration project called Ecovars (www.ecovars2.fr). We became involved in this partnership to increase the practical relevance of the knowledge we produce by contextualizing our scientific research. However, we show that achieving a change in our mode of knowledge production (from Mode-1 to Mode-2) requires a particular configuration of the partnership and partners who are pro-active. Putting Mode-2 into practice is not only a challenge for researchers but also for their partners.

\section{A CASE OF PARTNERSHIP RESEARCH IN ECOLOGICAL RESTORATION: THE ECOVARS PROJECT}

We were involved as researchers in the Ecovars project. This project was carried out as a partnership between experts in plant conservation, experts in seed production, and researchers in genetics and social sciences. The aim of Ecovars was to promote the use of local seeds for alpine grassland restoration in the Pyrenees mountains (Fig. 1).

\section{Context and Partnership of the Ecovars Project}

The idea of using local seeds for the restoration of alpine grasslands in the Pyrenees was first developed in the 1990s to restore small areas in the Pyrenean National Park (Fig. 2). In 1998, the Pyrenean Botanical Conservatory (PBC) recommended a generalized use of local seeds throughout the Pyrenees mountain range, in particular to restore plant cover after the construction of ski resorts. The use of non-local species for restoration may (i) increase the risk of a poor adaptation leading to technical failure, and (ii) provide a threat for local plant populations: mating between local and nonlocal genotypes can reduce the fitness of local plant progenies through gene swamping or outbreeding depression (Hufford and Mazer 2003). The use of local seeds appeared to be a good solution to avoid these problems. However, scaling up from the Park to the Pyrenean massif increased the amount of seeds needed and required the production of seeds of native species. The objectives were threefold: (i) choose and collect pioneer species whose ranges cover the massif, (ii) clarify what "local" entails by taking into account the genetic differentiation of the targeted species along the massif, and (iii) produce the seeds. To complete these tasks, the PBC and a geneticist from the French national institute of agronomy (INRA) set up the Ecovars project (20052008) (Fig. 2). This project was run by the PBC in partnership with INRA and the authority that coordinates agricultural development in the Pyrenees (SUAIA-P).

The project was organized in three work packages that corresponded to the expertise of each partner: consulting in restoration, information, and coordination (PBC), seed production (SUAIA-P), research and development (INRA) (Table 1). It was planned as a set of tasks to be accomplished by each partner (Table 1). The PBC managed the project and also provided expertise and technical support to seed users and to the French governmental authority that controls the type of seed mixture sown in restoration projects. The PBC was also responsible for communication on the project and for training seed users. The SUAIA-P was in charge of all aspects related to seed collection and production. Its task was based on the creation and management of a network of seed producers. They tested different cultural practices for native plants and applied the chosen practice for seed production. The INRA was in charge of genetic research into neutral and adaptive genetic structures of plant species to design seed transfer zones. Seed transfer zones are geographical regions within which the translocation of seeds of native species is supposed to have no detrimental effects on the restored population. 
Fig. 1. Map of the Pyrenees massif showing the alpine zone area.

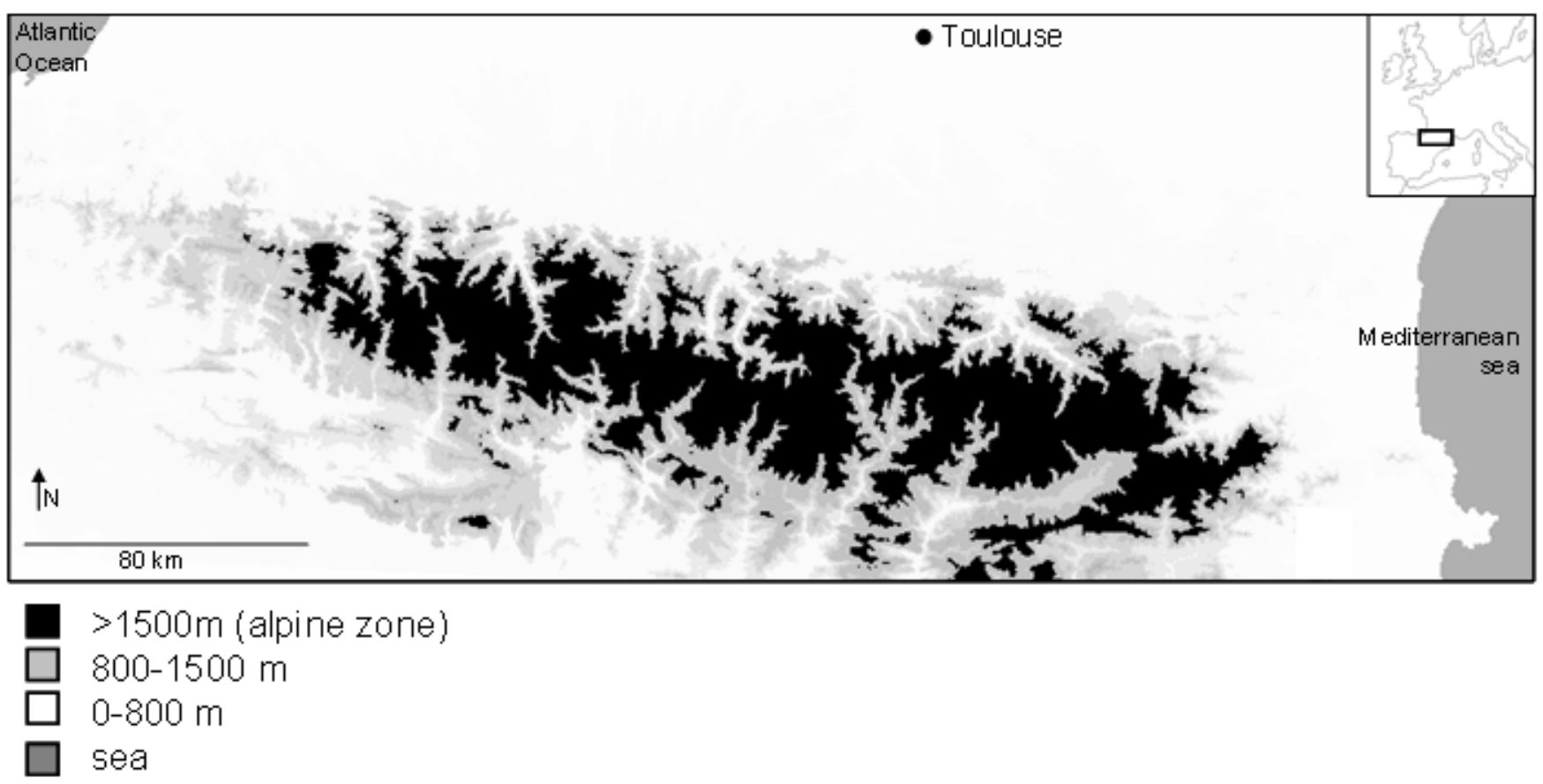

Designing these seed transfer zones was planned by social researchers from the INRA as a collaborative work with the main stakeholders. The INRA was also in charge of studying the dynamics of partnerships and the learning processes operating among the partners.

The three work packages were coordinated by an "operational group" consisting of a representative of each organization (Fig. 3). Each representative informed the other partners of the progress made by its organization. The operational group met monthly. An "executive group" was in charge of reviewing the progress of the project (Fig. 3) and was composed of the operational group together with the heads of the three organizations; they met once every trimester. Finally, a "supervising group" composed of the executive group, financial sponsors, and some stakeholders met yearly (Fig. 3).

\section{Focusing on the Relevance of Festuca eskia Seed Transfer Zones in the Ecovars Project}

In 2004, INRA geneticists initiated studies that would lead to the design of seed transfer zones. They worked on a fescue, Festuca eskia, which had been chosen to be the main component $(80 \%)$ of the future seed mixtures used in revegetation (Fig. 2). The choice of the native species to be produced and used in grassland revegetation was made by the $\mathrm{PBC}$ in 2001 (Fig. 2). The PBC chose pioneer species whose ranges cover the massif, like $F$. eskia. The aim of designating seed transfer zones for F. eskia was to determine zones within which seeds could be both collected for production and used in restoration with no genetic risk for the local populations. As a matter of fact, translocating seeds and plants from one place to another could alter the existing genetic differentiation between populations, swamp locally adapted genes and/or break-up co-adapted gene complexes in populations residing beside translocation sites. This is a population genetic concern applied to restoration (see review in 
Fig. 2. Chronology of the events before and during the Ecovars project.

\begin{tabular}{|lllll}
\hline \multicolumn{1}{|c|}{1998} & & \\
\hline
\end{tabular}

Hufford and Mazer 2003). The study involved (i) testing numbers of $F$. eskia populations over the Pyrenees with neutral genetic markers, and (ii) reciprocal transplant experiments to test for altitudinal adaptive differentiation between populations. However, the relevance of the F. eskia seed transfer zones as they were designed is questionable, firstly because these zones did not take into account unintentional selection occurring during the seed production process, and secondly because they failed to incorporate stakeholders' input.

The seed transfer zones lacked relevance because the unintentional selection that occurs during seed production was not taken into account. In 2005, the SUAIA-P initiated seed production of $F$. eskia and some other native species. During tests for different growing practices, the SUAIA-P experts noticed that the survival rate of $F$. eskia under cultivation conditions was not $100 \%$. As a consequence, these plants were not included in the seed production process whereas surviving plants were unintentionally selected. The project manager was informed but, because this was not considered as a crucial problem for establishing the growing practices for seed production, this issue was not discussed by the operational group. Later, in 2007, the researchers noticed that the survival rate in their experimental fields as well as the seed production of $F$. eskia under cultivation conditions depended on the origin of the plants: some F. eskia populations had a low survival rate or produced few seeds under cultivation conditions. At that time, the researchers saw that this constituted a critical constraint in the use of seed transfer zones: a seed transfer zone, to be of practical use, must include at least one source population that can be multiplied under cultivation conditions. As this variability of response to cultivation conditions had not been discussed previously by the partners, seed transfer zones were designed without taking into account this constraint. In the end, the seed transfer zone designed for $F$. eskia based on the results of population genetics turned out to be of little use.

The F. eskia seed transfer zones also lacked relevance with regard to the points of view of the stakeholders. In 2005, INRA social scientists 
Table 1. Organization of the Ecovars project in three work packages

\begin{tabular}{|c|c|c|c|c|}
\hline $\begin{array}{l}\text { Organization } \\
\text { Abbreviation }\end{array}$ & Description & Skills & $\begin{array}{l}\text { Work package in } \\
\text { Ecovars }\end{array}$ & Tasks \\
\hline $\mathrm{PBC}$ & $\begin{array}{l}\text { Pyrenean botanical } \\
\text { conservatory }\end{array}$ & $\begin{array}{l}\text { Experts in plant } \\
\text { conservation }\end{array}$ & $\begin{array}{l}\text { Expertise, information, } \\
\text { and coordination }\end{array}$ & $\begin{array}{l}\text { Leadership of the } \\
\text { Ecovars project } \\
\text { Technical expertise for } \\
\text { the restoration of } \\
\text { degraded alpine sites } \\
\text { Information and } \\
\text { communication on the } \\
\text { Ecovars project } \\
\text { Stakeholders network } \\
\text { management ( from } \\
\text { seed prescribers to seed } \\
\text { users) }\end{array}$ \\
\hline SUAIA-P & $\begin{array}{l}\text { Authority that } \\
\text { coordinates agricultural } \\
\text { development in the } \\
\text { Pyrenees }\end{array}$ & $\begin{array}{l}\text { Experts in seed } \\
\text { production }\end{array}$ & Seed production & $\begin{array}{l}\text { Seed collection of local } \\
\text { species at high altitude } \\
\text { Development of } \\
\text { methods for the seed } \\
\text { production of local } \\
\text { species } \\
\text { Development of a } \\
\text { network of seed } \\
\text { production farmers }\end{array}$ \\
\hline INRA & $\begin{array}{l}\text { French institute of } \\
\text { agronomical research }\end{array}$ & $\begin{array}{l}\text { Genetic and social } \\
\text { science researchers }\end{array}$ & $\begin{array}{l}\text { Research and } \\
\text { development }\end{array}$ & $\begin{array}{l}\text { Determination of the } \\
\text { genetic structure of } \\
\text { local plant populations } \\
\text { Study of factors that } \\
\text { could influence } \\
\text { population structure } \\
\text { Coordination for the } \\
\text { design of consensual } \\
\text { seed transfer zones } \\
\text { Examination of the } \\
\text { partnership }\end{array}$ \\
\hline
\end{tabular}

initiated a study involving a large diversity of stakeholders who restore degraded areas or who use restored places in the Pyrenees (Fig. 2). The objective was to integrate parameters such as the patrimonial value or the local use of alpine plant genetic resources in the design of seed transfer zones. Stakeholders (e.g., technicians who restore ski runs, livestock farmers) were interviewed to explain their use of the area to be restored and their opinion on the use of local plant species in its restoration. To their astonishment, the scientists learned from the stakeholders that $F$. eskia was "weeded from the ski slopes because it doesn't hold back the snow," it "triggers avalanches because it makes the snow slide," it creates slippery canopies that are dangerous for hikers, who called it the 
Fig. 3. Coordination of the Ecovars project.

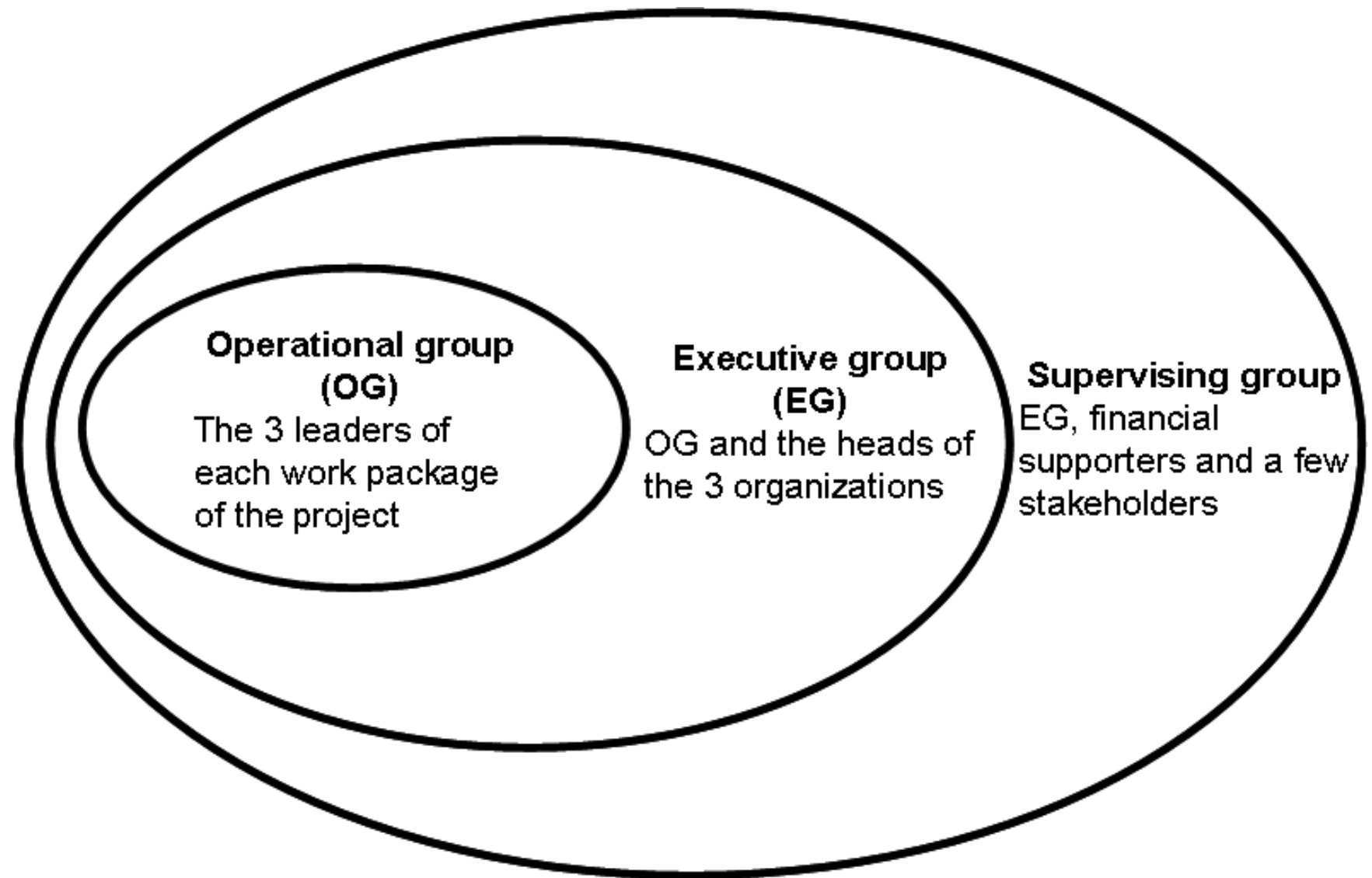

"killer grass," and "it is left by the sheep because they bleed from the muzzle when they graze on it." Consequently, in 2007, an enforced change in alpine species was made for the rest of the Ecovars project. However, the genetic research on $F$. eskia that had been initiated in 2004 could not now be switched to another species in 2007 because of the heavy workload involved. The research on $F$. eskia was pursued, but as a fundamental population genetics study.

\section{FINDINGS: WHAT WENT WRONG?}

Despite a well-designed organizational structure for the partnership in the Ecovars project (Table 1, Figs. 2 and 3 ), the coordination between the partners was insufficient to produce relevant knowledge with regard to the shared objectives of the project. This resulted, for example, in designing seed transfer zones without taking into account the unintentional selection that occurs during seed production. Three conditions could have facilitated the production of more relevant knowledge:

- $\quad$ setting up a reflexive discussion forum, i.e., a debating committee where each partner can expose and discuss his point of view and practices, integrating feedback from the other partners. In the Ecovars project, there was no structure that could serve as a forum for discussing our ideas, our values, and our different work practices: when results or problems were tackled by the operational group, they were transmitted as information rather than for group discussion. As a 
consequence, there was no co-production of knowledge by the Ecovars partners and this was a limiting factor in the relevance of the knowledge produced. Establishing a reflexive discussion forum requires a form of organization where there is less partitioning of tasks between work packages;

- interfacing the work packages. Even if the work packages in the Ecovars project were complementary, the fact that the each partner's tasks were partitioned in each work package reduced interactions;

- developing a "coordination" management style. The coordinator, while managing the partners and playing the role of decision maker, should also promote exchanges between partners and ensure that different points of view can be expressed for each question.

Moreover, despite collaborations with partners who know the field, the geneticists failed to produce knowledge that could be used to deal with a complex problem because the end users were not directly involved in the problem-finding process. However, the project partners found what appeared at the outset to be a clear research problem: what is the genetic differentiation of targeted species along the massif and which seed transfer zones can be used to preserve these differentiations? So, the geneticists worked in partnership with the PBC and the SUAIA-P, which were, more or less explicitly, the mouthpiece for the end users (seed users and seed producers). However, when considering the point of view of the end users on F. eskia, it became obvious that the definition of the problem was too restrictive, which led to an inappropriate initial choice of species by the PBC. If seed users, such as the technicians who restore ski runs, had been involved in the problem-finding process, they would have indicated their reluctance to sow F. eskia because it does not hold back the snow on the ski slopes. Furthermore, a discussion with stakeholders who use the restored area would also have revealed their reluctance vis-à-vis $F$. eskia. For example, the involvement of livestock farmers in problem finding might have given rise to a discussion on the palatability of different grass species that could be used to restore alpine areas maintained by grazing herds. The change in the chosen species in midproject could probably have been avoided if the partners in the project had held discussions with these other stakeholders early enough. The project partners could have taken into account the unavoidable constraints of the end users to identify the problem and its complexity. Thus, despite being involved in a real partnership, the project partners fell into the trap of a reductionist vision of a real, complex problem. The geneticists and experts of PBC and SUAIA-P alike, in limiting the problem to the conventional questions of academic disciplines (e.g., questions pertaining to population genetics) failed to contextualize. The consequence with regard to the research questions was that the experiments led to results that were of little practical relevance.

\section{DISCUSSION: RE-EXAMINING PARTNERSHIPS IN RESTORATION PROJECTS}

\section{Partner Diversity for a Relevant Plan of Action in Restoration Projects}

It is essential to have a diversity of stakeholders involved in problem finding and problem solving to grasp the full complexity of a problem. This is also essential to enable the implementation of a relevant plan of action. In the Ecovars project, partner diversity was too restricted to allow a real contextualization, especially of the scientific knowledge, and consequently hindered the production of knowledge relevant for the field work. Several research and development actions were launched but with a poor understanding of end-user expectations and of the social acceptability of the proposed solutions. This was the case when choosing F. eskia as the main species to be produced. Our experience reinforces and gives substance to the idea that Mode-2 knowledge production should start with a dialogue among a large number of different players to identify the problems (Nowotny et al. 2001). This early phase also gives the partners the opportunity to state their values and ethical motives and build the "common world" of the project. This is particularly important in ecological restoration because every time an ecosystem is restored, a particular view of nature is expressed (Higgs 2005).

Consequently, depending on who participates, the problem-finding and problem-solving processes may result in very different plans of action. The Ecovars project was initially aimed at large-scale seed production by the leading partner (PBC). This 
choice was not then discussed by the two other partners. A more comprehensive involvement of different stakeholders could have led to the problem being posed in completely different terms. The initial problem is that the construction of ski resorts destroys the plant cover. Rethinking construction techniques, saving topsoil and plant cover, which can later be returned to the degraded area, or promoting plant colonization from neighboring regions are other alternatives that could have been explored.

In return, the type of problem determines identification of the participants invited to take part in the process. Thus, there is a recursiveness between the definition of the questions and the participants involved. The problems, and the contexts in which they emerge, are never permanently fixed. Therefore, participants have to accept a form of inadequacy in the project formulations. This variability in context and problem requires a flexible and loose organizational structure of projects that is in contrast to the strict and partitioned tasks defined in projects like Ecovars. For this reason, it is not possible to formulate precise recommendations for setting up restoration projects.

Nevertheless, general principles can be defined for setting up appropriate partnerships. However, putting them into action requires a genuine effort to contextualize each particular case (van Aken 2005).

\section{Adopting Participatory Approaches to Partnerships that Promote Collective Learning}

Developing participatory approaches is likely to promote collective processes of problem finding and problem solving, which are the core processes of Mode-2. For several years now, researchers have been setting up participatory research structures to tackle complex problems of the real world. Although participatory research has been used in the fields of agriculture and natural resource management (e.g., Pretty 1995, Bawden 1997), it has been a fertile ground for development in ecological restoration (Light and Higgs 1996, Light 2000, Hagen et al. 2002). Although participatory approaches have in common the participation of different stakeholders, there are many interpretations of the term "participation" (Pretty 1995). Participation can be seen as a means to achieve the adoption of certain measures or orientations decided by those who are leading the project: this is manipulative participation. Conversely, selfmobilization is the extreme form of empowerment in which local actors coordinate their actions to solve a problem (Pretty 1995). Between these two extremes there is a gradient of approaches tending toward the setting up of "systems of learning and action" (Pretty 1995). Among these participatory approaches, we think that the ones focused on collective learning processes are more likely to facilitate the processes of problem finding and problem solving (e.g., Röling and Wagemakers 1998, LEARN-Group 2000, Couix 2002). The strategy of the project coordinator is then to involve all stakeholders (local actors, researchers, etc.) in a collective learning situation aimed at finding and solving problems. Our experience with the Ecovars project showed that the traditional management style and project structure failed to commit the three partners to a collective process of problem finding and problem solving.

These approaches require a conception of knowledge and learning different from the dominant approach (LEARN-Group 2000, Blackmore 2007). Simply put, this conception acknowledges:

- that knowledge no longer results exclusively from the academic production of researchers: all stakeholders have a knowledge production activity that may contribute to the formulation and resolution of problems. The aim of these approaches is to combine scientific and layman knowledge, or indeed to allow the coproduction of hybrid knowledge.

- the situational and highly contextual character of knowledge. Knowledge, in the theoretical framework of action or situated cognition (e.g., Suchman 1987, Cook and Brown 1999, Orlikowsky 2002, Gherardi 2006), is no longer considered as something stable that is presumably contained in the mind, but as a specific production in action tied to a specific context. Cook and Brown (1999), for example, propose moving from "the epistemology of possession [...] towards an epistemology of practices." Thus, knowledge is always rebuilt in action, through daily practices: "knowing is practicing” (Gherardi 2006). 


\section{Moving from Knowledge Transfer to Knowledge Co-Production in Restoration Projects}

The above perspective on participative systems of learning and action challenges the notion of knowledge transfer. Knowledge is usually considered as something that can be transferred from scientists to practitioners provided that a good communication technique is used. However, according to many authors, knowledge is not passed down from scientists to practitioners; practitioners reconstruct knowledge in their daily activities. Cook and Brown (1999) consider "knowledge as a tool of knowing" that can be mobilized in the action during which "we are seeking what we need in order to do what we want to do." Orlikowsky (2002) makes the more radical claim that no form of knowledge is transferable. At best, information or data can be transferred. According to this author, "sharing 'knowing how' can be seen as a process of enabling others to learn the practice that entails the 'knowing how'. It is a process of helping others develop the ability to enact-in a variety of contexts and conditions - the knowing in practice."

Consequently, it is important to reconsider the role of researchers within participatory approaches, particularly in terms of knowledge production. It is no longer a question of knowledge transfer from the researchers to the other participants but a question of knowledge co-production. For example, the lack of relevance of the seed transfer zones designed in the Ecovars project is partly attributable to the fact that they were not co-constructed. The seed transfer zones should not have been designed "in the lab" to be applied or even adapted to the field, but directly co-designed in a process involving at the very least the other participants of the project and at best several other stakeholders. The role of researchers in participatory approaches should not only be to help find and solve technical problems but also to facilitate learning processes among the participants (LEARN-Group 2000).

In return, participatory approaches imply a real involvement of the other participants too. They should abandon the conventional and passive posture that consists of submitting a problem and waiting for a "good to go" solution. So, participatory approaches presuppose a profound transformation of the role developed by the organizations dedicated to the transfer of knowledge. The project manager, whether a researcher or not, has to become a coordinator and a facilitator, and go beyond the standard role of leader or boss, encouraging new ways of thinking about problems and collective learning. These transformations are not straightforward and may involve a real collective learning process (LEARN-Group 2000, Steyaert and Ollivier 2007).

In conclusion, we would say that, if the need for participatory approaches that promote collective and reflexive processes of problem finding and problem solving is becoming widely acknowledged in conservation and restoration projects, putting such processes into practice is not only a challenge for the researchers but also for the researchers' partners. In other words, changing the knowledge production from Mode-1 to Mode-2 (Gibbons et al. 1994) does not depend only on researchers who have to change their research practices but also on the other actors who should enter the participatory process. It presupposes a profound transformation of the role of each partner in such projects.

Responses to this article can be read online at:

http://www.ecologyandsociety.org/voll3/iss2/art53/responses/

\section{Acknowledgments:}

Thanks to F. Healy for translating the manuscript and improving the English. This paper is part of $H$. G. $-T$.'s PhD dissertation.

\section{LITERATURE CITED}

Bawden, R. 1997. Learning to persist. A systemic view of development. Pages 1-5 in F. A. Stowell, J. Holloway, and R. I. Ison, editors. Systems for sustainability. Plenum Publishing Corporation, New York, New York, USA.

Blackmore, C. 2007. What kinds of knowledge, knowing and learning are required for addressing resource dilemmas: a theoretical overview. Environmental Science and Policy 10(6):512-525.

Cabin, R. J. 2007. Science-driven restoration: a square grid on a round earth? Restoration Ecology 15:1-7.

Chan, K. M. A., R. M. Pringle, J. A. I. Ranganathan, C. L. Boggs, Y. L. Chan, P. R. Ehrlich, P. K. Haff, N. E. Heller, K. A. R. I. Al 
Khafaji, and D. P. Macmynowsky. 2007. When agendas collide: human welfare and biological conservation. Conservation Biology 21:59-68.

Choi, Y. D. 2007. Restoration ecology to the future: a call for a new paradigm. Restoration Ecology 15 (2):351-353

Cook, S. D. N., and J. S. Brown. 1999. Bridging epistemologies: the generative dance between organizational knowledge and organizational knowing. Organization Science 10(4):381-400.

Couix, N. 2002. Concerted approach to land-use management: developing common working procedures. A Cevennes case study (France). Land Use Policy 19(1):75-90.

Geist, C., and S. M. Glatowitsch. 1999. Reciprocal model for meeting ecological and human needs in restoration projects. Conservation Biology 13:970979.

Gherardi, S. 2006. Organizational knowledge. The texture of workplace learning. Blackwell Publishing, London, UK.

Gibbons, M., C. Limoges, H. Nowotny, S. Schwartzman, P. Scott, and M. Trow. 1994. The new production of knowledge: the dynamics of science and research in contemporary societies. Sage Publications, London, UK.

Gobster, P. H., and R. B. Hull. 1999. The restoration and management of nature. A conference and forthcoming book explore restoration from the perspectives of the social sciences and humanities. Ecological Restoration 17:44-51.

Hagen, D., J. Aasetre, and L. Emmelin. 2002. Communicative approaches to restoration ecology: a case study from Dovre Moutain and Svalbard, Norway. Landscape Research 27:359-380.

Hessels, L. K. and H. van Lente. 2008. Re-thinking new knowledge production: a literature review and a research agenda. Research Policy 37(4):740-760.

Higgs, E. 1997. What is good ecological restoration? Conservation Biology 1:338-348.

Higgs, E. 2005. The two-culture problem: ecological restoration and the integration of knowledge. Restoration Ecology 13:159-164.
Hufford, K. M., and S. J. Mazer. 2003. Plant ecotypes: genetic differentiation in the age of ecological restoration. Trends in Ecology and Evolution 18(3):147-155.

LEARN-Group. 2000. Cow up a tree. Knowing and learning for change in agriculture. Case studies from industrialised countries. INRA Editions, Paris, France.

Light, A. 2000. Restoration, the value of participation and the risks of professionalization. Pages 163-181 in P. H. Gobster and R. B. Hull, editors, Restoring nature. Perspectives from the social sciences and humanities. Island Press, Washington, D.C., USA.

Light, A., and E. Higgs. 1996. The politics of ecological restoration. Environmental Ethics 18:227-47

Nowotny, H., P. Scott, and M. Gibbons. 2001. Rethinking science. Knowledge and the public in an age of uncertainty. First edition. Sage Publications, London, UK.

Orlikowski, W. J. 2002. Knowing in practice: enacting a collective capability in distributed organizing. Organization Science 13(3):249-73.

Pretty, J. N. 1995. Participatory learning for sustainable agriculture. World Development 23 (8):1247-1263.

Rhoades R. 1989. The role of farmers in the creation of appropriate technology. Pages 3-9 in R. Chambers, R. Pacey, and L. Thrupp, editors, Farmer first: farmer innovation and agricultural research. Intermediate Technology Publications, London, UK.

Robertson, D. P., and R. B. Hull. 2001. Beyond biology: toward a more public ecology for conservation. Conservation Biology 15:970-979.

Robinson, J. G. 2006. Conservation biology and real-world conservation. Conservation Biology 20:658-669.

Röling, N., and M. A. E. Wagemakers, editors. 1998. Social learning for sustainable agriculture. Cambridge University Press, Cambridge, UK.

Steyaert, P., and G. Ollivier. 2007. The European Water Framework Directive : how ecological 
assumptions frame technical and social change. Ecology and Society 12(1): 25. [online] URL:http:// www.ecologyandsociety.org/vol12/iss1/art25/.

Suchman, L. 1987. Plans and situated actions. The problem of human-machine communication. First edition. Cambridge University Press, Cambridge, UK.

Temperton, V. M. 2007. The recent double paradigm shift in restoration ecology. Restoration Ecology 15(2):344-347.

van Aken, J. E. 2005. Management research as a design science: articulating the research products of Mode-2 knowledge production in management. British Journal of Management 16:19-36. 